\title{
MAPEAMENTO DO USO E OCUPAÇÃO DO SOLO NA MICROBACIA DO CÓRREGO DO KARAMACY - ITAPEVA/SP.
}

Nome do Autor (a) Principal

Amanda Aparecida de Lima.

Nome (s) do Coautor (a) (s)

NatháliaJanjácomo da Mota; Andressa Oliveira Matos.

Nome (s) do Orientador (a) (s)

Yara Manfrin Garcia.

Instituição ou Empresa

Universidade Estadual Paulista "Júlio de Mesquita Filho" - UNESP/FCA, Botucatu

E-mail de contato: aalima2603@gmail.com

Palavras-chave

Sistemas de Informação Geográfica.Uso e Ocupação do Solo.Microbacia Hidrográfica.

\section{INTRODUÇÃO}

O crescimento da população tem causado uma pressão cada vez maior sobre os cursos d'água, principalmente em regiões metropolitanas. Os usos do solo são muito importantes às diversas características desses cursos d'água, no qual determinam o nível trófico do ambiente (XAVIER, 2005).

Os recursos naturais sofrem um desequilíbrio juntamente com a mudança da dinâmica da água no solo por meio da demasiada taxa do uso do solo em áreas de 
cultivo que fazem uso intensivo de mecanização. O mapa de uso e ocupação gerados em estudo dos solospermite uma melhor visualização, possibilitando um diagnóstico para tomadas de decisões que trazem a longevidade, além da melhor gestão de seus recursos (GOMES et al., 2007).

Desta forma, torna-se relevante realizar estudos em regiões onde a utilização agrária do solo é intensa. Logo, destaca-se o município de Itapeva, estado de São Paulo, que é considerado como uns dos polos comerciais do Sudoeste Paulista por meio do crescimento econômico e social e possui grande produção de madeira, onde são realizadas as práticas de monocultura de Pinus e Eucalipto.

Com o auxílio das geotecnologias, por meio do Sistema de Informação Geográfica (SIG) e do Sensoriamento Remoto (SR) é possível a partir de cartas digitais planialtimétricas e de imagem de satélite determinar a devida localização geográfica de uma microbacia, além da identificação e delimitação de seus diferentes usos e ocupação do solo e outros elementos da área em estudo.

Assim, torna-se possível a criação de mapas e tabelas para auxiliar na análise e interpretação dos dados levantados.

\section{OBJETIVO GERAL}

O presente estudo tem como objetivo identificar os diferentes tipos de uso e ocupação do solo da microbacia do córrego do Karamacy localizada em Itapeva, SP.

\section{Objetivos Específicos}

Quantificar os usos do solo dentro da microbacia do córrego do Karamacy fazendo uso das geotecnologias de Sistema de Informação Geográfica e Sensoriamento Remoto. E pretende-se com essas informações, a realização de novos estudos, que como este, se colocados em prática beneficiarão o meio ambiente. 


\section{METODOLOGIA}

O município de Itapeva, localizado no interior do estado de São Paulo, é conhecido como "capital dos minérios" ocupa uma área de $1827 \mathrm{~km}^{2}$ com aproximadamente 90 mil habitantes (ITAPEVA, 2014).

A microbacia do Córrego do Karamacy localiza-se no município de Itapeva $\mathrm{SP}$, entre as coordenadas geográficas $23^{\circ} 53^{\prime} 13.81^{\prime \prime}$ a $23^{\circ} 52^{\prime} 33.98^{\prime \prime}$ de latitude S e $48^{\circ} 53^{\prime} 44.12^{\prime \prime}$ a $48^{\circ} 50^{\prime} 58.24^{\prime \prime}$ de longitude WGr.; e entre as coordenadas UTM E= $7355000 \mathrm{~m}$ a $7362000 \mathrm{~m}$ e $\mathrm{N}=713000 \mathrm{~m}$ a $719000 \mathrm{~m}$.

A base cartográfica utilizada foi a carta planialtimétrica em formato digital, editada pelo Instituto Brasileiro de Geografia e Estatística, IBGE (1973) tendo como sistema de referência o Córrego Alegre (antigo datum planimétrico brasileiro), referente a folha de Itapeva (SF-22-Z-D-V- 3) em escala 1:50.000. A imagem de satélite, de novembro de 2013, utilizada foi proveniente do Landsat-08 com sensor OLI (Operational Land Imager) e TIRS (Thermallnfrared Sensor) fornecida pelo Departmentofthe Interior/ U.S. GeologicalSurvey, no qual se encontram em operação, sete bandas espectrais que, para o presente estudo, foi usado três dentre essas bandas: 6, 5 e 4, composição RGB (Red, Green e Red), essa composição traz melhor visualização para descriminação dos alvos.

Para o processamento das informações, georreferenciamento, composições coloridas da imagem de satélite em RGB, conversão dos dados de vetoriais para raster, elaboração dos mapas de uso e ocupação do solo e gerar os buffers de APPs, foi utilizado o Sistema de Informações Geográficas - IDRISI Selva. E, para a construção da base dos dados relacionais na forma de pontos, linhas e polígonos, utilizou-se o software CartaLinx, desenvolvido pela Clark University. Além disso, fezse uso das imagens do Google Earth para obter uma melhor interpretação da composição.

Como primeira etapa realizou-se o georreferenciamento utilizando as imagens de satélite, bandas 6,5 e 4 , já com base na carta planialtimétrica previamentegeorreferenciada. Após essa etapa, faz-se o recorte da imagem extraindo somente a área da microbacia que, logo após, foi feita a composição da imagem RGB (Figura 1). De acordo com Figueiredo(2005), a composição colorida 
trata-se de um dos artifícios de maior utilidade na interpretação das informações do Sensoriamento Remoto.

Figura 1: Composição RGB das bandas da área de estudo.

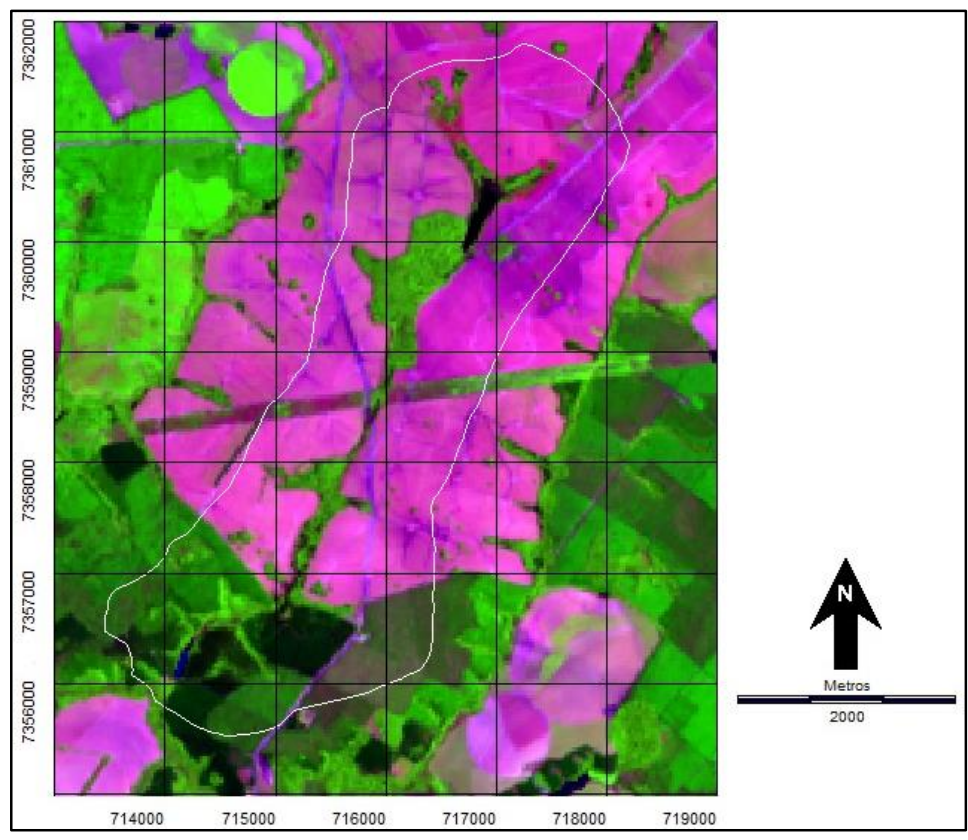

No CartaLinx, para a criação dos polígonos de cobertura, criou-se uma tabela com códigos referente as classes de uso. Após essa etapa, exportou-se para o IDRISI edeterminou-se as áreas de cada uso.

\section{RESULTADOS}

$\mathrm{Na}$ Figura 2 tem-se o mapa de uso e ocupação do solo na microbacia do córrego do Karamacy e constatou-se oito classes de uso. 
Figura 2: Mapa de Uso e Ocupação do Solo da microbacia do córrego do Karamacy.

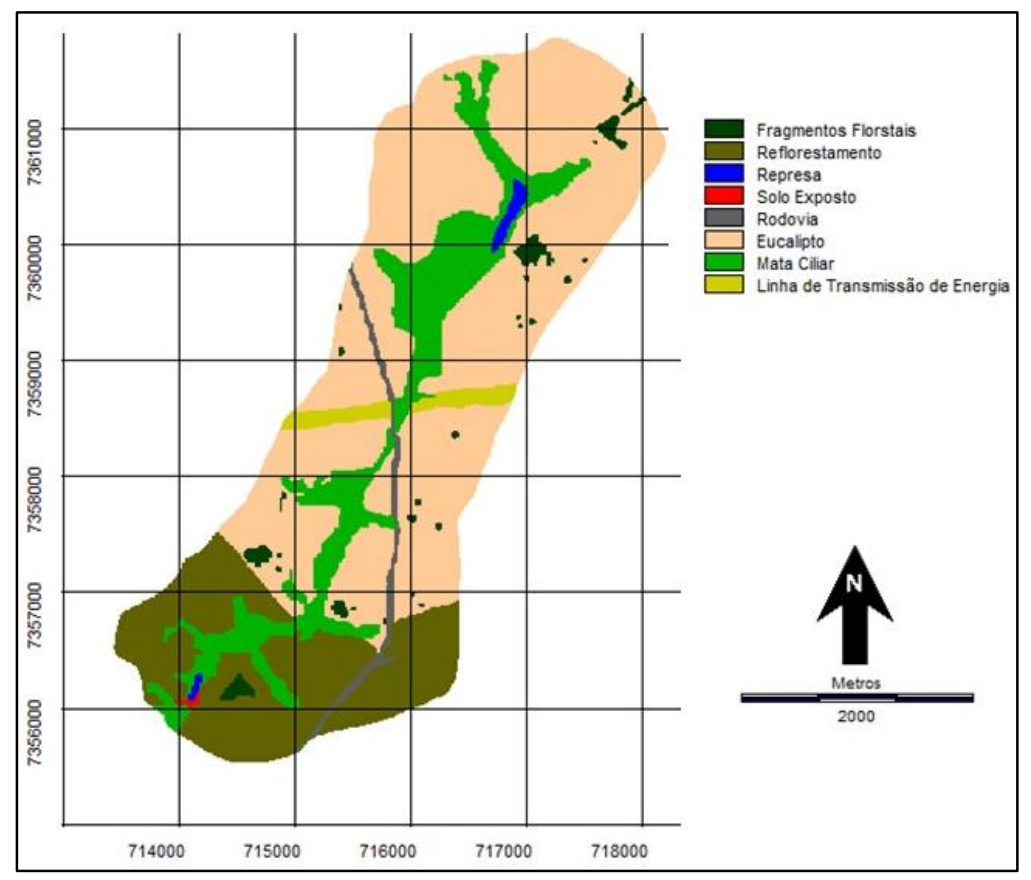

A maior área de uso e ocupação do solo corresponde a classe de eucalipto, que apresenta 734,92ha de eucalipto derrubado; a área de reflorestamento segue com 266,47ha de eucalipto em pé; a mata ciliar ocupa uma área de 207,73ha; a linha de transmissão de energia abrange 25,35ha as terras; os fragmentos florestais 23,69ha; a rodovia 22,68ha; as áreas da represa são de 7,72ha; e o solo exposto é de 1,0ha (Tabela 1).

Tabela 1:Tabela de uso e ocupação do solo da microbacia do córrego do Karamacy.

\begin{tabular}{lcc}
\hline Classes de Uso e Ocupação do Solo & Área & \\
\hline & (ha) & $\%$ \\
Fragmentos Florestais & 23,69 & 1,84 \\
Reflorestamento & 266,47 & 20,66 \\
Represa & 7,72 & 0,60 \\
Solo Exposto & 1,00 & 0,08 \\
Rodovia & 22,68 & 1,76 \\
Eucalipto & 734,92 & 57,0 \\
Mata Ciliar & 207,73 & 16,11 \\
Linha de Transmissão de Energia & 25,35 & 1,96 \\
\hline Total & $\mathbf{1 . 2 8 9 , 5 1}$ & $\mathbf{1 0 0}$ \\
\hline
\end{tabular}




\section{CONCLUSÃO}

Quanto aos usos e ocupações do solo, foram identificadas oito classes, os fragmentosflorestais, reflorestamento, represa, solo exposto, rodovia, eucalipto, mata ciliar e a linha detransmissão, mais conhecida como "Linhão".

A maior área de uso foi o reflorestamento com 266,47ha, resultando num total de20,66\% em relação ao total dos usos da microbacia de estudo.

As geotecnologias SIG e SR foram essenciais para a realização da pesquisa, fazendopossível realizar todas as operações necessárias para identificar e quantificar todos os usos eocupações do solo.

\section{REFERÊNCIAS}

FIGUEIREDO, D. Conceitos Básicos de Sensoriamento Remoto. CompanhiaNacional de Abastecimento - CONAB. Brasília - DF. 2005. Disponível em:

<http://www.conab.gov.br/conabweb/download/SIGABRASIL/manuais/conceitos_sm. pdf>. Acesso em: 10 out. 2014.

GOMES, N. M.; FARIA, M. A.; SILVA, A. M.; MELLO, C. R.; VIOLA, M. R.Variabilidade espacial de atributos físicos do solo associados ao uso e ocupação dapaisagem.Revista Brasileira de Engenharia Agrícola e Ambiental. CampinaGrande, PB, 2007. V. 11, n.4, p. 427 - 435. Disponível em:

<http://www.scielo.br/pdf/rbeaa/v11n4/v11n04a13.pdf>. Acesso em: 15 out. 2014.

IBGE. Instituto Brasileiro de Geografia e Estatística. Carta topográfica: folha deltapeva (SF-22-Z-DV-3). Serviço gráfico do IBGE, 1974. Escala 1:50.000.ITAPEVA. História e Perfil da Cidade. 2014. Disponível em:

<http://www.itapeva.sp.gov.br/conheca-itapeva/historia/>. Acesso em: 15 out. 2014.

ITAPEVA. História e Perfil da Cidade. 2014. Disponível em:

<http://www.itapeva.sp.gov.br/conheca-itapeva/historia/>. Acesso em: 15 out. 2014.

XAVIER, C. F. Avaliação da Influência do Uso e Ocupação do Solo e deCaracterísticas Geomorfológicas Sobre a Qualidade das Águas de DoisReservatórios da Região Metropolitana de Curitiba - Paraná. Dissertação paraMestrado. Universidade Federal do Paraná - UFPR, Curitiba, PR, 167p. 2005. 